\title{
Can the Gold Standard Be Beaten? How Reliable Are Various Modifications of the Synacthen Test Compared to the Insulin Tolerance Test
}

\author{
M. KOSAK ${ }^{2}$, M. DUSKOVA ${ }^{1}$, L. STARKA ${ }^{1}$, H. JANDIKOVA ${ }^{1}$, H. POSPISILOVA ${ }^{1}$, \\ M. SRAMKOVA ${ }^{1}$, V. HANA ${ }^{2}$, M. KRSEK ${ }^{4}$, D. SPRINGER ${ }^{3}$, K. SIMUNKOVA ${ }^{1,2}$ \\ ${ }^{1}$ Institute of Endocrinology, Prague, Czech Republic, ${ }^{2}$ Third Department of Medicine, Department \\ of Endocrinology and Metabolism, First Faculty of Medicine, Charles University and General \\ University Hospital in Prague, Czech Republic, ${ }^{3}$ Institute of Medical Biochemistry and Laboratory \\ Diagnostics, First Faculty of Medicine, Charles University and General University Hospital in \\ Prague, Czech Republic, ${ }^{4}$ Second Department of Medicine, Third Faculty of Medicine, Charles \\ University and University Hospital Královské Vinohrady, Prague, Czech Republic
}

Received May 20, 2017

Accepted June 27, 2017

\section{Summary}

Criteria for the evaluation of the insulin tolerance test (ITT) and Synacthen test are still a matter of debate. The objective of the study was to make a comparison of serum and salivary cortisol during four stimulation tests. Sixty four healthy volunteers underwent the ITT, the Synacthen test with 1 (LDST), 10 (MDST) and 250 (HDST) $\mu \mathrm{g}$ dose of ACTH. Maximum serum cortisol response was observed at the $90 \mathrm{~min}$ of the ITT (49\%), HDST ( $89 \%$ ) and MDST (56 \%) and at the 40 min of the LDST (44\%). Results expressed as $95 \%$ confidence intervals: 408.0-843.6 and $289.5-868.1 \mathrm{nmol} / \mathrm{l}$ in the IIT at 60 and $90 \mathrm{~min}$. In the HDST and the MDST serum cortisol reached the maximum at $90 \mathrm{~min}$ 542.6-1245.5 and 444.2-871.3 nmol/l. Levels of salivary cortisol followed the same pattern as serum cortisol. Salivary cortisol reached the maximum response in the HDST and the MDST at $90 \mathrm{~min}$ and at $40 \mathrm{~min}$ in the LDST. We confirmed good reliability of all tests with respect to timing of response and maximum response compared to the ITT. We proved that the MDST test can provide the similar response in serum cortisol to the HDST. Measuring either salivary cortisol or ACTH levels did not provide any additional benefit then measuring serum cortisol by itself.

\section{Key words}

Insulin tolerance test - Synacthen tests - Serum cortisol • Salivary cortisol

\section{Corresponding author}

K. Simunkova, Institute of Endocrinology, Narodni 8, Prague 1, 116 94, Czech Republic. E-mail: ksimunkova@gmail.com

\section{Introduction}

Assessments of hypothalamic-pituitary-adrenal (HPA) axis insufficiency are an ongoing challenge. Misdiagnoses of adrenal insufficiency (AI) because of false negative stimulation test results should be minimized by using an optimal test with the highest sensitivity and specificity.

The gold standard is still regarded to be the insulin tolerance test (ITT), but the cut-off level for the ITT is still unclear. In many centres the ITT is avoided due to several limitations. An easily performed alternative, the Synacthen test, was introduced 45 years ago, but there are still a lot of controversies and issues about the choice of test.

Moreover, it is still unknown whether morning cortisol can sufficiently predict adrenal gland capacity. A morning serum cortisol (SeC) below cut-off of $103 \mathrm{nmol} / 1$ (Deutschbein et al. 2009) and over $381 \mathrm{nmol} / 1$ were suggested (Maguire et al. 2008, Hana et al. 2015). In such cases, if AI is still suspected, then a stimulation test is recommended.

The standard Synacthen test (HDST) is usually 
performed with a $250 \mu \mathrm{g}$ dose of ACTH (Ospina et al. 2016). Nevertheless, this dose can overstimulate the adrenal gland, particularly in cases of a mild form of AI, and can cause difficulties with diagnosis. To avoid misinterpretation, it has been suggested to use a more physiological dose of Synacthen. The dose $1 \mu \mathrm{g}$ of Synacthen (the low dose Synacthen test, LDST) has also been widely used, but this test has got many pitfalls.

The selection of either the HDST or LDST is still a controversial topic. There is a lack of standard protocols for the performance of the LDST, the methods of Synacthen administration, timing of the blood test or the cut-off (Wallace et al. 2009, Chatha et al. 2010). The $1 \mu \mathrm{g}$ ACTH dose can only be applied intravenously. Only $24 \%$ of the $1 \mu \mathrm{g}$ dose may reach circulation administered intramuscularly (Dickstein 1998). The loss of ACTH during reconstitution of commercial ampule and during application is a crucial argument against the LDST (Dickstein et al. 2008, Murphy et al. 1998). Dickstein also examined the question of ACTH stability in low concentration solutions and confirmed its stability and biological efficacy (Dickstein et al. 2008).

Our interventional/observational study aimed to compare the response of cortisol in serum and saliva to the ITT and to three doses of Synacthen. We also tested medium dose $10 \mu \mathrm{g}$ of Synacthen whether it may provide a sufficient response and decrease misdiagnosis of AI. We attempt to answer the still-unresolved question of the best test of HPA insufficiency.

\section{Subjects and Methods}

Eligible participants were recruited by a poster in the Institute of Endocrinology, Prague, Czech Republic. 64 healthy volunteers (33 men, 31 women) with mean age 41.4 and mean BMI $25.5 \mathrm{~kg} / \mathrm{m}^{2}$, with no history of endocrine disorder, serious disease, treatment with corticosteroids and estrogens were included. All subjects signed informed consent forms prior to inclusion. The study was approved by the Regional Ethical committee, and performed according to the principles of Good Clinical Practice (CPMP/ICH/135/95).

The following tests were performed consecutively, with a minimum interval of one week between each test: ITT $(n=57)$, HDST $(n=62)$, MDST $(\mathrm{n}=61)$ and LDST $(\mathrm{n}=64)$ and in the morning hours (08:00-09:00) after overnight fasting.

An intravenous cannula was inserted in the forearm vein. After $30 \mathrm{~min}$ of rest a baseline blood and saliva sample were taken (time 0 ) and then serum and saliva samples were taken simultaneously at defined intervals during each test. We evaluated serum cortisol $(\mathrm{SeC})$ and salivary cortisol $(\mathrm{SaC})$ and, in addition, ACTH and CRH during the ITT.

For the ITT, insulin (Humulin R, Eli Lilly, Indianapolis, IN, USA) was administered intravenously at a dose of $0.15 \mathrm{IU}$ per $\mathrm{kg}$ of body weight. Blood samples were taken at $20,30,40,60,90$ and 120 min after the administration of insulin.

ACTH (tetracosactid $250 \mu \mathrm{g} / 1 \mathrm{ml}$, Synacthen, Novartis) was used for each Synacthen test. A standard commercial ampule of Synacthen was reconstituted to doses of $10 \mu \mathrm{g}$ and $1 \mu \mathrm{g}$ ACTH right before each test by adding $250 \mathrm{ml}$ of isotonic saline, respectively, to the $250 \mu \mathrm{g} \mathrm{ACTH} / 1 \mathrm{ml}$ ampule.

For the HDST, a standard dose of $250 \mu \mathrm{g}$ of ACTH was administered intravenously and then blood was drawn at 30,60 and $90 \mathrm{~min}$.

For the medium dose Synacthen test (MDST), $10 \mathrm{ml}$ of diluted Synacthen solution (diluted as described above) containing $10 \mu \mathrm{g}$ of $\mathrm{ACTH}$ were administered intravenously and then blood samples were drawn at 30 , 60 and $90 \mathrm{~min}$.

The LDST was performed by intravenous administration of $1 \mathrm{ml}$ of Synacthen solution (diluted as described above) containing $1 \mu \mathrm{g}$ of ACTH. Blood samples were drawn at 20, 30, 40 and $60 \mathrm{~min}$.

Blood samples were taken into Vacuette tubes (plastic tubes for sampling coagulating blood with a coagulation activator and separation gel). Serum was obtained by centrifugation for $5 \mathrm{~min}$ at $2000 \mathrm{~g}$ at $4{ }^{\circ} \mathrm{C}$, and then stored at $-20^{\circ} \mathrm{C}$. Saliva was sampled at regular intervals during each test. Saliva samples were collected in Sarstedt Salivette saliva examination tubes type 51.1534 , centrifuged for $5 \mathrm{~min}$ at $2000 \mathrm{~g}$ at $4^{\circ} \mathrm{C}$, and frozen at $-20^{\circ} \mathrm{C}$.

\section{Laboratory method}

Serum and salivary cortisol were analyzed by the chemiluminiscent immunoassay (CLIA) Centaur XP Siemens (CLIA) method. Sensitivity was $5.5 \mathrm{nmol} / \mathrm{l}$.

ACTH was analyzed by IRMA kits (Brahms Diagnostica, Hennigsdorf, Germany). Sensitivity was $1.2 \mathrm{pg} / \mathrm{ml}$. The intra- and interassay variability was less than $5.0 \%$ and $10.0 \%$, respectively.

Corticotropin Releasing Factor (CRH) was analyzed by RIA kits (Phoenix Pharmaceuticals, Inc, 
Karlsruhe, Germany). The sensitivity of the CRF RIA kit was $23.9 \pm 2.5 \mathrm{pg} /$ tube. The interassay and within-assay variation coefficients at $16 \mathrm{pg} /$ tube were $8.4 \%$ and $3.8 \%$, respectively.

\section{Statistical analysis}

Statistical analysis was performed using the STATISTICA Version 12 (StatSoft Inc, Prague, Czech Republic) program. Confidence interval was obtained using MedCalc software, version 12.7.7.0 (MedCalc software, Mariakerke, Belgium).

\section{Results}

\section{Serum cortisol (SeC)}

ITT

$95 \%$ of subjects achieved $\mathrm{SeC}$ levels of over $500 \mathrm{nmol} / 1$ at $60 \mathrm{~min}$. The remaining three (5\%) subjects had SeC levels of 427, 494 and $484 \mathrm{nmol} / 1$ at $60 \mathrm{~min}$; this was the maximum response for two of them $(3.4 \%)$, the third subject reached a level of over $500 \mathrm{nmol} / 1$ at $90 \mathrm{~min}$. Two false positive results were detected in the ITT. Surprisingly, these subjects achieved a normal response in all three Synacthen tests. $84 \%$ of subjects reached $\mathrm{SeC}$ levels over $550 \mathrm{nmol} / \mathrm{l}$, and $72 \%$ were over $600 \mathrm{nmol} / 1$ at $60 \mathrm{~min}, 61 \%$ at $40 \mathrm{~min}$, and $90 \%$ were over $500 \mathrm{nmol} / \mathrm{l}$ at $90 \mathrm{~min}$. All subjects reached sufficient hypoglycemia during the ITT.

\section{HDST}

All subjects reached $\mathrm{SeC}$ levels of over $500 \mathrm{nmol} / 1$ after stimulation with $250 \mu \mathrm{g}$ of Synacthen at $60 \mathrm{~min}$ and at $90 \mathrm{~min} .97 \%$ of subjects at $30 \mathrm{~min} .98 \%$ and $97 \%$ subjects at $60 \mathrm{~min}$ and $90 \mathrm{~min}$ had $\mathrm{SeC}$ over $550 \mathrm{nmol} / \mathrm{l}$, respectively.
MDST

$98 \%$ subjects exceeded the cut-off $500 \mathrm{nmol} / 1$, $97 \%$ over $550 \mathrm{nmol} / 1$ at $60 \mathrm{~min}$.

$95 \%$ were over $500 \mathrm{nmol} / 1$ and $79 \%$ over $550 \mathrm{nmol} / 1$ at $30 \mathrm{~min}$. At $90 \mathrm{~min}, 97 \%$ were over $500 \mathrm{nmol} / 1,92 \%$ over $550 \mathrm{nmol} / 1$, and $89 \%$ over $600 \mathrm{nmol} / 1$.

\section{$L D S T$}

At $60 \mathrm{~min}$, only $67 \%$ of subjects had reached a SeC level of over $500 \mathrm{nmol} / \mathrm{l}$, though $48 \%$ over $550 \mathrm{nmol} / 1$.

A vast majority of subjects, $98 \%$ and $86 \%$, were over $500 \mathrm{nmol} / 1$ and $550 \mathrm{nmol} / 1$ at $40 \mathrm{~min}$, respectively.

$95 \%$ and $86 \%$ of the subjects were over $500 \mathrm{nmol} / 1$ and $550 \mathrm{nmol} / 1$ at $30 \mathrm{~min}$, respectively.

At $20 \mathrm{~min}, 92 \%$ and $83 \%$ were over $500 \mathrm{nmol} / 1$ and $550 \mathrm{nmol} / \mathrm{l}$.

One subject reached a $\mathrm{SeC}$ over $500 \mathrm{nmol} / \mathrm{l}$ by 20 min and then $\mathrm{SeC}$ gradually declined.

More details are shown in Table 1 and Figures 1, 2, 3 and 4 .

Distribution of the maximal $\mathrm{SeC}$ response in all tests

The distribution of maximum $\mathrm{SeC}$ responses according to the time of occurrence differed in all of the tests. The prevalence of the maximum response was $49 \%$ at $90 \mathrm{~min}$ during the ITT, $89 \%$ at $90 \mathrm{~min}$ during the HDST, $56 \%$ at $90 \mathrm{~min}$ during the MDST, and $44 \%$ at $40 \mathrm{~min}$ during the LDST. The LDST had the widest maximal response distribution of all tests. For more details see Table 2 .

Table 1. Serum cortisol levels $(\mathrm{nmol} / \mathrm{l})$ at basal condition and after the stimulation expressed as $95 \%$ confidence intervals.

\begin{tabular}{lcccc}
\hline & ITT & HDST & MDST & LDST \\
\hline Confidence interval \% & $2.5-97.5$ & $2.5-97.5$ & $2.5-97.5$ & $2.5-97.5$ \\
$0 \mathrm{~min}$ & $184.8-610.7$ & $170.8-653.6$ & $159.1-584.0$ & $132.3-660.1$ \\
$20 \mathrm{~min}$ & $161.6-557.3$ & - & - & $444.5-808.6$ \\
$30 \mathrm{~min}$ & $137.7-596.6$ & $484.5-991.4$ & $476.2-719.1$ & $490.1-786.8$ \\
$40 \mathrm{~min}$ & $242.0-698.7$ & - & - & $501.1-771.7$ \\
$60 \mathrm{~min}$ & $408.0-843.6$ & $554.6-1013.8$ & $508.6-839.3$ & $341.9-775.5$ \\
$90 \mathrm{~min}$ & $289.5-868.1$ & $542.6-1245.5$ & $444.2-871.3$ & - \\
$120 \mathrm{~min}$ & $307.4-827.2$ & - & - & - \\
\hline
\end{tabular}



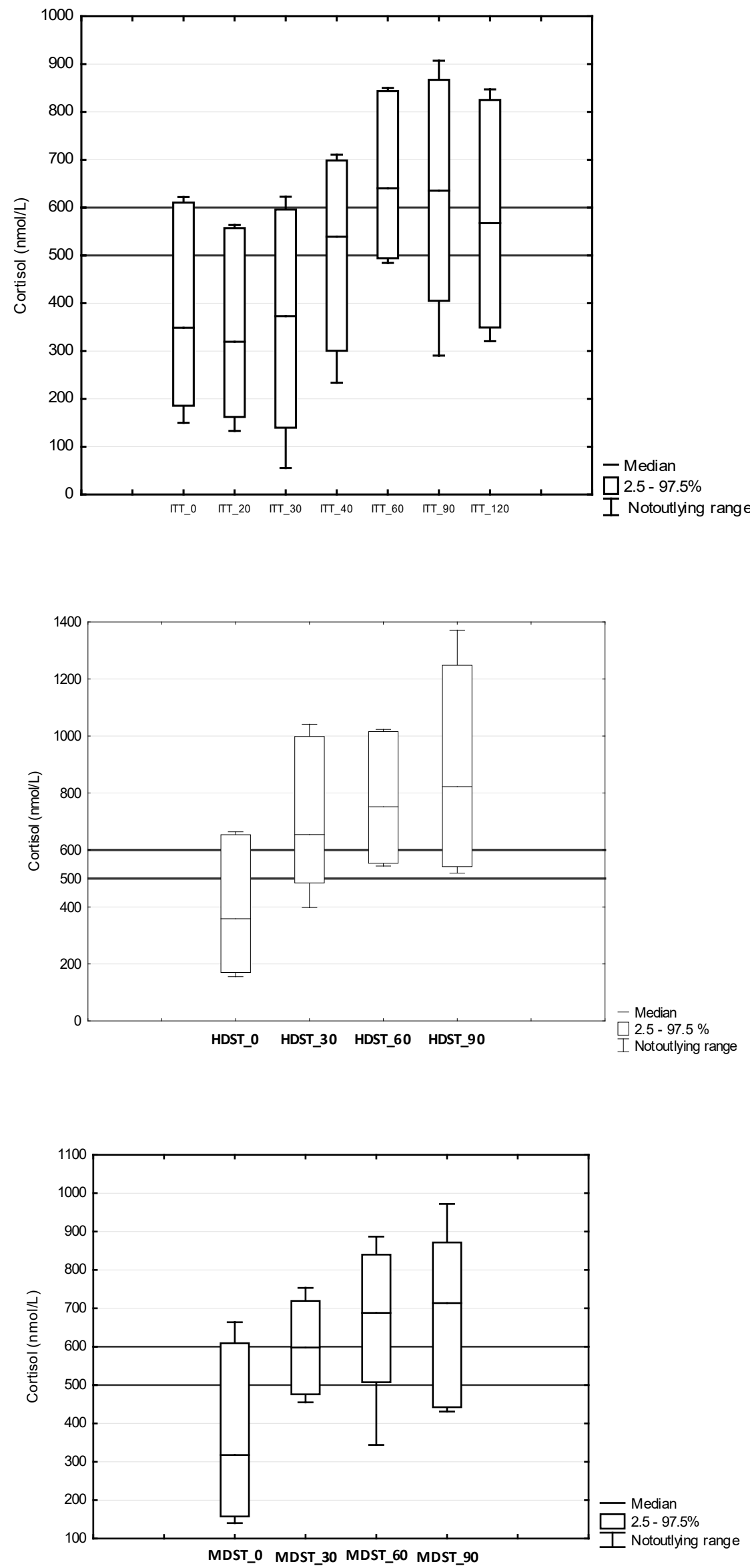

Fig. 1. Serum cortisol levels during the ITT. Cut off limits of 500 and $600 \mathrm{nmol} / \mathrm{l}$ are shown.

Fig. 2. Serum cortisol levels during the HDST. Cut off limits of 500 and $600 \mathrm{nmol} / \mathrm{l}$ are shown.

Fig. 3. Serum cortisol levels during the MDST. Cut off limits of 500 and $600 \mathrm{nmol} / \mathrm{l}$ are shown. 


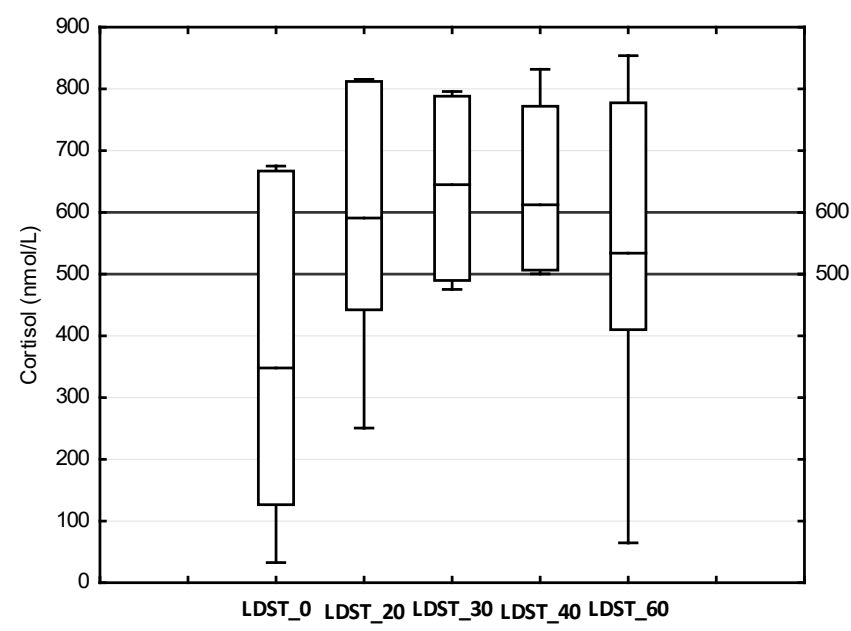

Fig. 4. Serum cortisol levels during the LDST. Cut off limits of 500 and $600 \mathrm{nmol} / \mathrm{l}$ are shown.

Table 2. Number of subjects reaching used cut off for serum cortisol for evaluation of stimulation test.

\begin{tabular}{llll}
\hline & $>\mathbf{5 0 0} \mathbf{~ n m o l} / \mathbf{l}$ & $>\mathbf{5 5 0} \mathbf{~ m o l} / \mathbf{l}$ & $>\mathbf{6 0 0} \mathbf{~ n m o l} / \mathbf{l}$ \\
\hline$H D S T-60 \mathrm{~min}$ & $62 / 62(100 \%)$ & $61 / 62(98.4 \%)$ & $58 / 62(93.5 \%)$ \\
$H D S T-90 \mathrm{~min}$ & $62 / 62(100 \%)$ & $60 / 62(96.8 \%)$ & $58 / 62(93.5 \%)$ \\
$M D S T-60 \mathrm{~min}$ & $60 / 61(98.4 \%)$ & $59 / 61(96.7 \%)$ & $53 / 61(86.9 \%)$ \\
$M D S T-90 \mathrm{~min}$ & $59 / 61(96.7 \%)$ & $56 / 61(91.8 \%)$ & $54 / 61(88.5 \%)$ \\
$L D S T-30 \mathrm{~min}$ & $61 / 64(95.3 \%)$ & $55 / 64(85.9 \%)$ & $43 / 64(67.2 \%)$ \\
$L D S T-40 \mathrm{~min}$ & $63 / 64(98.4 \%)$ & $55 / 64(85.9 \%)$ & $40 / 64(62.5 \%)$ \\
$I T T-60 \mathrm{~min}$ & $54 / 57(94.7 \%)$ & $48 / 57(84.2 \%)$ & $41 / 57(71.9 \%)$ \\
$I T T-90 \mathrm{~min}$ & $51 / 57(89.5 \%)$ & $44 / 57(77.2 \%)$ & $36 / 57(63.2 \%)$ \\
\hline
\end{tabular}

Table 3. Salivary cortisol levels $(\mathrm{nmol} / \mathrm{l})$ at basal condition and after the stimulation expressed as $95 \%$ confidence intervals.

\begin{tabular}{lcccc}
\hline & ITT & HDST & MDST & LDST \\
\hline Confidence interval \% & $2.5-97.5$ & $2.5-97.5$ & $2.5-97.5$ & $2.5-97.5$ \\
$0 \mathrm{~min}$ & $3.7-51.6$ & $2.5-42.0$ & $3.7-33.9$ & $2.0-45.4$ \\
$20 \mathrm{~min}$ & $3.2-51.6$ & - & - & $5.2-72.2$ \\
$30 \mathrm{~min}$ & $3.3-50.3$ & $7.9-97.3$ & $9.0-82.1$ & $8.1-76.6$ \\
$40 \mathrm{~min}$ & $4.7-61.1$ & - & - & $10.4-76.9$ \\
$60 \mathrm{~min}$ & $9.6-73.6$ & $12.1-126.0$ & $15.7-105.0$ & $7.0-59.9$ \\
$90 \mathrm{~min}$ & $8.9-78.0$ & $12.1-158.4$ & $12.5-114.7$ & - \\
$120 \mathrm{~min}$ & $5.5-96.3$ & - & - & - \\
\hline
\end{tabular}

\section{Salivary cortisol ( $\mathrm{SaC})$}

ITT

Cortisol increments during the ITT expressed as $95 \%$ confidence intervals are shown in Table 3. The range between the lowest and highest $\mathrm{SaC}$ levels was quite wide $(3.38-55.35 \mathrm{nmol} / \mathrm{l}) .7$ out of 35 subjects
(20\%) provided adequate amount of saliva during the ITT and had low levels of salivary cortisol during the entire ITT, failing to reach the suggested cut-off $20 \mathrm{nmol} / 1$ (Contreras et al. 2004). For the remainder of the subjects, the maximal response of $\mathrm{SaC}$ was observed at $90 \mathrm{~min}$ (median $45.79 \mathrm{nmol} / \mathrm{l}$ ). 


\section{ACTH tests}

The $\mathrm{SaC}$ concentration correlated with $\mathrm{SeC}$, and the maximal responses of $\mathrm{SaC}$ after Synacthen stimulations were similar to $\mathrm{SeC}$. The maximal responses of $\mathrm{SaC}$ were observed at $90 \mathrm{~min}$ during the HDST, at 60 min during the MDST and at 30 min during the LDST.

\section{CRH and ACTH during the ITT}

The results of $\mathrm{CRH}$ reaction to insulin-induced hypoglycemia were heterogeneous and inconclusive. The maximum response of ACTH in ITT was observed at $40 \mathrm{~min}$ (median $258.6 \mathrm{nmol} / \mathrm{l}$ ) then ACTH rapidly declined. Results expressed as median ACTH concentrations during the ITT were $23.7 \mathrm{ng} / 1$ at baseline, and $25.5,45.1,258.6,256.9,56.9$ and $29.6 \mathrm{ng} / 1$ at 20, 30, 40, 60, 90 and $120 \mathrm{~min}$, respectively.

\section{Discussion}

The ITT showed similar results as the HDST and MDST tests in the percentage of subjects with sufficient responses with respect to the time of occurrence and cutoff. The same cut-offs for cortisol during the LDST were reached earlier, however, mostly at 30 and $40 \mathrm{~min}$. This confirmed that the cortisol response is dose dependent (Dickstein et al. 1991) and that the MDST can provide comparable responses as the HDST. The percentage of false positives in all tests increased with increased cut-off levels of serum cortisol. We used three different cut-offs of cortisol for all 4 tests to evaluate the sensitivity of these cut-off levels, and logged the time that a response occurred. During the LSDT the maximal stimulated cortisol response is found between 20 and $30 \mathrm{~min}$ and during the HDST between 60 and 90 min (Nye et al. 1999, Rasmuson et al. 1996, Patel et al. 1999). Nevertheless, current recommendation for evaluation of maximum response is still 20 and $30 \mathrm{~min}$ for the LSDT and at $30 \mathrm{~min}$ for the HDST. Based on other dose response studies (Crowley et al. 1991, Dickstein et al. 1997) we decided to follow the cortisol response to 3 different ACTH stimuli for 90 min during the HDST and MDST tests, and more frequently for $60 \mathrm{~min}$ during the LDST. During the LDST the highest prevalence of maximal $\mathrm{SeC}$ response was at $40 \mathrm{~min}(44 \%)$, compared to at $90 \mathrm{~min}$ during the MDST and HDST (maximal responses of $56 \%$ and $89 \%$, respectively). Our results support frequent sampling during the first hour of the LDST. An additional blood test at 90 min during the MDST and HDST should also be considered. During the
ITT sampling at the $120 \mathrm{~min}$ it may be necessary to obtain a maximal $\mathrm{SeC}$ response. These delayed maximal $\mathrm{SeC}$ responses may be used to exclude AI or they may indicate mild AI and may be the first sign of AI (Dickstein et al. 1991, Park et al. 1999).

Interpretation of results and their specificity particularly depends on determining the maximal stimulated cortisol concentration or the lowest limit for a normal adrenal response (maximal response, cut-off). Generally, in healthy individuals the $\mathrm{SeC}$ response after administering $1 \mu \mathrm{g}$ and $250 \mu \mathrm{g}$ ACTH ranges from $390-770 \mathrm{nmol} / 1$ (Patel et al. 1999). However, no agreement yet exists on the cut-off limit of maximal serum cortisol response after stimulation. Some authors suggested $500 \mathrm{nmol} / 1$, others $550 \mathrm{nmol} / 1$ or even $600 \mathrm{nmol} / 1$ (Hurel et al. 1996, Metha et al. 2005, Cho et al. 2014). Partial AI, with maximal cortisol levels from 510 to $550 \mathrm{nmol} / \mathrm{l}$, is a term used by some authors (Agha et al. 2006). We evaluated the applicability of the three most frequently-used $\mathrm{SeC}$ cut-offs of 500, 550 and $600 \mathrm{nmol} / 1$. Our results showed that the cut-off $500 \mathrm{nmol} / 1$ was most frequently reached in the ITT and LDST, the cut-off $550 \mathrm{nmol} / 1$ in the MDST, and $600 \mathrm{nmol} / 1$ in the HDST, regardless of the time of occurrence. Cortisol levels of $500-550 \mathrm{nmol} / 1$ were considered to be a maximal increase upon stimulation by $1 \mu \mathrm{g} \mathrm{ACTH}$ that corresponds to adrenal stimulation after the ITT with sensitivity of $94 \%$ and specificity of $90 \%$ (Tordjman et al. 2000, Rasmuson et al. 1996, Dickstein et al. 2001). We consider $\mathrm{SeC}$ level cut-off of $500 \mathrm{nmol} / 1$ for the LDST to be the optimal cut-off for distinguishing patients with an intact HPA. Based on our results, higher levels of 550 or even $600 \mathrm{nmol} / 1$, as suggested by Abdu et al. (1999) would be inappropriate in terms of higher number of false negative results.

Generally, the maximal stimulated cortisol response occurs $30 \mathrm{~min}$ after the administration of 0.5-1 $\mu \mathrm{g}$ of ACTH (Dickstein et al. 1991) and $60 \mathrm{~min}$ after $250 \mu \mathrm{g}$ of ACTH. In our study, the HDST as well as the MDST showed the highest frequency for a $\mathrm{SeC}$ response (over $500 \mathrm{nmol} / \mathrm{l}$ ) at 60 and $90 \mathrm{~min}$. For the LDST maximal $\mathrm{SeC}$ levels were reached earlier, at 30 and $40 \mathrm{~min}$, in line with the results of previous studies. According to the cut-off values and timing used in our study, the MDST gave a similar $\mathrm{SeC}$ response as the HDST. Unfortunately we did not follow $\mathrm{SeC}$ up to 120 min during those tests.

The question about comparability of ACTH tests and the ITT is still being studied; numerous studies 
showed good correlation between $1 \mu \mathrm{g}$ ACTH and the ITT, while other studies found that the ITT causes a greater maximal cortisol increase (Dickstein et al. 1991, Rasmuson et al. 1996, Gonzálbez et al. 2000, Giordano et al. 2008). One explanation may be insufficient hypoglycemia reached during the ITT (Hurel et al. 1996). In our study, the LDST provided similar response of the $\mathrm{SeC}$ as the ITT and, interestingly, 2 subjects failed to reach $\mathrm{SeC}$ over $500 \mathrm{nmol} / \mathrm{l}$ despite achieving adequate hypoglycemia.

Administration of $1 \mu \mathrm{g}$ ACTH 1-24 resulted in similar levels of ACTH $100 \mathrm{ng} / \mathrm{l}$ in circulation as during the ITT (Alia et al. 2006, Nye et al. 1999). In our study, ACTH exceeded $100 \mathrm{ng} / \mathrm{l}$, and the maximum SeC response was reached between 60 and $120 \mathrm{~min}$ with the highest prevalence $(49 \%)$ at 60 min. Our median ACTH was $256.9 \mathrm{ng} / \mathrm{l}$ at $60 \mathrm{~min}$ during the ITT, confirming proper ITT performance with all subjects achieving sufficient low-blood glucose levels. The two subjects failed to reach $\mathrm{SeC}$ levels of over $500 \mathrm{nmol} / 1$ (maximal responses were 427 and $494 \mathrm{nmol} / \mathrm{l}$ ) and did not differ in their severity of hypoglycemia (1.3 and $1.2 \mathrm{nmol} / \mathrm{l})$ or in BMI (20.1 and 28.5). Corresponding maximal ACTH levels in these subjects were 108.4 and $69.6 \mathrm{ng} / \mathrm{l}$.

Making the interpretation of results even more difficult is the fact that there are circumstances that can lead to altered levels of cortisol binding proteins and albumin. The $\mathrm{SaC}$ measurement was introduced to circumvent this issue. One study has suggested a $\mathrm{SaC}$ cut-off of about $20 \mathrm{nmol} / \mathrm{l}$, but no clear cut-off limit for adrenal insufficiency has yet been published (Contreras et al. 2004). Saliva cortisol levels are currently only useful as an additional tool for assessing HPA axis insufficiency. Compared to a previous study (Kosak et al. 2014), with $250 \mu \mathrm{g}$ of Synacthen we found lower $\mathrm{SaC}$ values of 2.9-42 nmol/1 before the test, and a wider range of $\mathrm{SaC}$ levels after stimulation: 7.93-97.2 $\mathrm{nmol} / \mathrm{l}$ at $30 \mathrm{~min}$ and 12.1-126.0 $\mathrm{nmol} / \mathrm{l}$ at $60 \mathrm{~min}$ (data expressed as $95 \%$ confidence intervals). Therefore, measurements of $\mathrm{SaC}$ levels gave no additional benefit over serum cortisol, regardless of the type of test.

Additionally, the influence of gender on cortisol response has yet to be quantified (Roca et al. 2005, Roelfsema et al. 1993). We did not find a difference in
$\mathrm{SeC}$ response between men and women, and age was also excluded as an additional confounding factor.

Our assessment of CRH during the ITT confirmed previous observations that $\mathrm{CRH}$ levels in the periphery do not correlate, because extra-hypothalamic sources of CRH contribute to serum levels (Jeske et al. 1989). Measuring ACTH along with SeC during the ITT did not give any advantage for assessing the HPA axis (Born et al. 2003), ACTH correlated with $\mathrm{SeC}$ during the ITT. However, we do not suggest replacing $\mathrm{SeC}$ with ACTH measurements. At most, an evaluation of ACTH might be used as an additional marker during the ITT in some borderline clinical cases.

\section{Conclusions}

All the tests provided reliable evaluations of the HPA axis but each test needs its own cut-off. However, our data lacks comparisons with an appropriate group of patients with AI.

Our results suggest that the MDST may replace the HDST, with additional blood samples at $90 \mathrm{~min}$. Moreover, blood tests during the LDST must be performed more frequently.

Salivary cortisol assessments did not show any benefits and we found no superiority of $\mathrm{SaC}$ over $\mathrm{SeC}$ in these stimulation tests. Synacthen test, especially MDST, may be suggested as a first - choice test in suspicion not only for primary, but also for secondary adrenal insufficiency with serum cortisol level $500 \mathrm{nmol} / \mathrm{l}$ as a sufficient cut-off limit.

\section{Conflict of Interest}

There is no conflict of interest.

\section{Acknowledgements}

This study was supported by the MEYS CR (OP RDE, Excellent research - ENDO.CZ), by $\mathrm{MH} \mathrm{CZ} \mathrm{-} \mathrm{DRO}$ (Institute of Endocrinology - EU, 00023761) from the Ministry of Health of the Czech Republic and by grant UNCE 204022 from the Charles University in Prague and NS NT 1127-7. We thank all healthy volunteers for their participation as well as the study nurses for their kind help.

\section{References}

ABDU TA, ELHADD TA, NEARY R, CLAYTON RN: Comparison of the low dose short synacthen test (1 microg), the conventional dose short synacthen test $(250 \mathrm{microg})$, and the insulin tolerance test for assessment of the hypothalamo-pituitary-adrenal axis in patients with pituitary disease. J Clin Endocrinol Metab 84: 838-843, 1999. 
AGHA A, TOMLINSON JW, CLARK PM, HOLDER G, STEWART PM: The long-term predictive accuracy of the short synacthen (corticotropin) stimulation test for assessment of the hypothalamic-pituitary-adrenal axis. J Clin Endocrinol Metab 91: 43-47, 2006.

ALÍA P, VILLABONA C, GIMÉNEZ O, SOSPEDRA E, SOLER J, NAVARRO MA: Profile, mean residence time of ACTH and cortisol responses after low and standard ACTH tests in healthy volunteers. Clin Endocrinol (Oxf) 65: 346-351, 2006.

CHATHA KK, MIDDLE JG, KILPATRICK ES: National UK audit of the short synacthen test. Ann Clin Biochem 47: 158-164, 2010.

CHO HY, KIM JH, KIM SW, SHIN CS, PARK KS, KIM SW: Different cut-off values of the insulin tolerance test, the high-dose short Synacthen test $(250 \mu \mathrm{g})$ and the low-dose short Synacthen test $(1 \mu \mathrm{g})$ in assessing central adrenal insufficiency. Clin Endocrinol (Oxf) 81: 77-84, 2014.

CLARK PM, NEYLON I, RAGGATT PR, SHEPPARD MC, STEWART PM: Defining the normal cortisol response to the short Synacthen test: implications for the investigation of hypothalamic-pituitary disorders. Clin Endocrinol (Oxf) 49: 287-292, 1998.

CONTRERAS LN, ARREGGER AL, PERSI GG, GONZALEZ NS, CARDOSO EM: A new less-invasive and more informative low-dose ACTH test: salivary steroids in response to intramuscular corticotrophin. Clin Endocrinol (Oxf) 61: 675-682, 2004.

CROWLEY S, HINDMARSH PC, HOLOWNIA P, HONOUR JW, BROOK CG: The use of low doses of ACTH in the investigation of adrenal function in man. J Endocrinol 130: 475-479, 1991.

DEUTSCHBEIN T, UNGER N, MANN K, PETERSENN S: Diagnosis of secondary adrenal insufficiency: unstimulated early morning cortisol in saliva and serum in comparison with the insulin tolerance test. Horm Metab Res 41: 834-839, 2009.

DICKSTEIN G: The low dose (1 microgram) ACTH test - when and how to use it. Clin Endocrinol (Oxf) 49: 135, 1998.

DICKSTEIN G: Peak cortisol response to insulin tolerance test: how reproducible is it really? Clin Endocrinol (Oxf) 55: 819-820, 2001.

DICKSTEIN G, SAIEGH L: Low-dose and high-dose adrenocorticotropin testing: indications and shortcomings. Curr Opin Endocrinol Diabetes Obes 15: 244-249, 2008.

DICKSTEIN G, SHECHNER C, NICHOLSON WE, ROSNER I, SHEN-ORR Z, ADAWI F: Adrenocorticotropin stimulation test: effects of basal cortisol level, time of day, and suggested new sensitive low dose test. $J$ Clin Endocrinol Metab 72: 773-778, 1991.

DICKSTEIN G, SPIGEL D, ARAD E, SHECHNER C: One microgram is the lowest ACTH dose to cause a maximal cortisol response. There is no diurnal variation of cortisol response to submaximal ACTH stimulation. Eur $J$ Endocrinol 137: 172-175, 1997.

GIORDANO R, PICU A, BONELLI L, BALBO M, BERARDELLI R, MARINAZZO E: Hypothalamus-pituitaryadrenal axis evaluation in patients with hypothalamo-pituitary disorders: comparison of different provocative tests. Clin Endocrinol (Oxf) 68: 935-941, 2008.

GONZÁlBEZ J, VILLABONA C, RAMÓN J, NAVARRO MA, GIMÉNEZ O, RICART W: Establishment of reference values for standard dose short synacthen test (250 microgram), low dose short synacthen test (1 microgram) and insulin tolerance test for assessment of the hypothalamo-pituitary-adrenal axis in normal subjects. Clin Endocrinol (Oxf) 53: 199-204, 2000.

HÁNA V JR, JEŽKOVÁ J, KOSÁK M, KRŠEK M, MAREK J, NETUKA D, HILL M, HÁNA V: Prediction of adrenocortical insufficiency after pituitary adenoma surgery using postoperative basal cortisol levels. Physiol Res 64: 531-536, 2015.

HUREL SJ, THOMPSON CJ, WATSON MJ, HARRIS MM, BAYLIS PH, KENDALL-TAYLOR P: The short Synacthen and insulin stress tests in the assessment of the hypothalamic-pituitary-adrenal axis. Clin Endocrinol (Oxf) 44: 141-146, 1996.

JESKE W, SOSZYŃSKI P, ROGOZIŃSKI W, LUKASZEWICZ E, LATOSZEWSKA W, SNOCHOWSKA H: Plasma GHRH, CRH, ACTH, beta-endorphin, human placental lactogen, GH and cortisol concentrations at the third trimester of pregnancy. Acta Endocrinol (Copenh) 120: 785-789, 1989. 
KOSÁK M, HÁNA V, HILL M, SIMU゚NKOVÁ K, LACINOVÁ Z, KRŠEK M: Serum cortisol seems to be a more appropriate marker for adrenocortical reserve evaluation in ACTH test in comparison to salivary cortisol. Physiol Res 63: 229-236, 2014.

MAGUIRE AM, BIESHEUVEL CJ, AMBLER GR, MOORE B, MCLEAN M, COWELL CT: Evaluation of adrenal function using the human corticotrophin-releasing hormone test, low dose Synacthen test and 9am cortisol level in children and adolescents with central adrenal insufficiency. Clin Endocrinol (Oxf) 68: 683-691, 2008.

MEHTA A, HINDMARSH PC, DATTANI MT: An update on the biochemical diagnosis of congenital ACTH insufficiency. Clin Endocrinol (Oxf) 62: 307-314, 2005.

MURPHY H, LIVESEY J, ESPINER EA, DONALD RA: The low dose ACTH test - a further word of caution. $J$ Clin Endocrinol Metab 83: 712-713, 1998.

NYE EJ, GRICE JE, HOCKINGS GI, STRAKOSCH CR, CROSBIE GV, WALTERS MM: Comparison of adrenocorticotropin (ACTH) stimulation tests and insulin hypoglycemia in normal humans: low dose, standard high dose, and 8-hour ACTH-(1-24) infusion tests. J Clin Endocrinol Metab 84: 3648-3655, 1999.

OSPINA NS, AL NOFAL A, BANCOS I, JAVED A, BENKHADRA K, KAPOOR E, LTEIF AN, NATT N, MURAD $\mathrm{MH}$ : ACTH stimulation tests for the diagnosis of adrenal insufficiency: systematic review and meta-analysis. J Clin Endocrinol Metab 101: 427-434, 2016.

PARK YJ, PARK KS, KIM JH, SHIN CS, KIM SY, LEE HK: Reproducibility of the cortisol response to stimulation with the low dose (1 microg) of ACTH. Clin Endocrinol (Oxf) 51: 153-158, 1999.

PATEL L, CLAYTON PE: Clinical usefulness of the low dose ACTH test. J Endocrinol Invest 22: 401-404, 1999.

RASMUSON S, OLSSON T, HAGG E: A low dose ACTH test to assess the function of the hypothalamic-pituitaryadrenal axis. Clin Endocrinol (Oxf) 44: 151-156, 1996.

ROCA CA, SCHMIDT PJ, DEUSTER PA, DANACEAU MA, ALTEMUS M, PUTNAM K, CHROUSOS GP, NIEMAN LK, RUBINOW DR: Sex-related differences in stimulated hypothalamic-pituitary-adrenal axis during induced gonadal suppression. J Clin Endocrinol Metab 90: 4224-4231, 2005.

TORDJMAN K, JAFFE A, TROSTANETSKY Y, GREENMAN Y, LIMOR R, STERN N: Low-dose (1 microgram) adrenocorticotrophin (ACTH) stimulation as a screening test for impaired hypothalamo-pituitary-adrenal axis function: sensitivity, specificity and accuracy in comparison with the high-dose (250 microgram) test. Clin Endocrinol (Oxf) 52: 633-640, 2000.

WALLACE I, CUNNINGHAM S, LINDSAY J: The diagnosis and investigation of adrenal insufficiency in adults. Ann Clin Biochem 46: 351-367, 2009. 